\title{
The use of statistics to define taxonomies of film voices: a practical approach to documentary classification
}

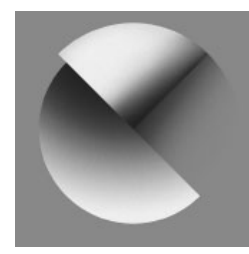

\author{
SERGio Villanueva BASElgaid, MARIO PEREZ-MONTORO \\ AND LYDIA SÁNCHEZ \\ University of Barcelona, Spain
}

\begin{abstract}
A B S TRACT
The study of visual content using qualitative methods currently involves much scholarly work in the field of digital humanities. Documentary films are considered among those objects defined as visual content and are therefore not the focus of most attention within Film Studies. One of the bestknown researchers in this area, Bill Nichols, proposed a theoretical classification of six documentary voices that is widely recognized in academic circles. However, the classification is based on induction and intuition which, until now, have not been verified in accordance with the evidence. This study proposes a mixed qualitative and quantitative methodology that allows the authors to surpass Nichols' model and generate a new classification based on empirical criteria. To that end, they study the opinions of users of and experts on Nichols' theory through the card sorting technique borrowed from cognitive science that is based on multivariate statistics. In this way, they generate a hierarchy of formal cinematographic elements grouped into four documentary voices and Nicholas' classification proposal is partly replaced as two of the voices in his model disappear but the four others are confirmed. In addition, this new model allows the authors to determine which formal elements are assigned to each one of the confirmed documentary modes and with what relative weights, thereby opening up the possibility of generating a predictive model. The article therefore demonstrates that cluster analysis and other techniques borrowed from multivariate statistics can be used to empirically and quantitatively verify theories in film studies as well as in other areas such as poetics. This suggests that it is possible to verify empirically and use quantitative models for the study of visual content and complement other methods based on induction and intuition.
\end{abstract}

\section{KEYWORDS}

card sorting • cluster analysis • documentary film • study of film visual documentary $\bullet$ taxonomies 


\section{INTRODUCTION}

When the term 'documentary' is mentioned, what comes into most readers' minds is perhaps Grierson's definition, 'creative treatment of the actual' (Chapan, 2006) or even Bill Nichols' (2006) classification of documentaries within the field of Film Theory or the definition of documentary. It is important to emphasize, nevertheless, that documentaries and other visual content such as narrative films, poetry, and so on, go beyond mere expression of the artistic charm and the 'creative treatment of actuality' to take on the responsibility of communication and cultural import. Unfortunately, the definition of what should constitute a documentary seems limited. On this account, those in the field of Film Study have traditionally linked documentaries to humanities, and so the methods adopted are based on narrative inquiry and comparative qualitative analysis.

Thus, the nature of documentary has been widely discussed using these tools, but has rarely been approached from a quantitative perspective. More revealing is that the use of statistical tools to study cinema has mostly centred on techniques of market analysis, such as studying an audience's preference for films of certain genres (Hsu, 2006), the legitimacy of opinion networks in the success of films (Cattani et al., 2008), innovation in the dynamics of investment (Ferrari and Rudd, 2008) or the significance of cinematographic works through a sophisticated algorithm (Wasserman et al., 2015). However, as early as the 1970s, Barry Salt (1974) was daring enough to discuss very wellgrounded theoretical aspects concerning the nature of cinema using quantitative approaches. Since then, some approaches to the quantitative study of the nature of cinema have taken form, such as those adopted in the Cinemetrics project, for example (Tsivian, 2009).

Owing to the lack of alternative approaches, digital humanities are facing the challenge of finding qualitative methods that can be of application for visual content. Therefore, the main objective of this study is to introduce a protocol for a quantitative methodology for analysis of a classification of documentary films but one that can be expanded to other cultural content. Specifically, this study will examine one of the most well-founded theories of the nature of documentary cinema - that of Bill Nichols. The combination of quantitative and qualitative methodological procedures will allow a systematization of the taxonomy of documentaries developed by Nichols and permit us to discuss some of the voices that he defends. The objective is to analyse Nichols' documentary classifications with a view to understanding whether all the six classifications are relevant and reflect on the emerging and new forms of documentaries in other areas. This was achieved by studying the opinions of users of and experts on Nichols' theory through the card sorting technique, which was borrowed from cognitive science and is based on multivariate statistics.

\section{NICHOLS' DOCUMENTARY VOICES}

Bill Nichols carried out one of the most important classifications of documentaries within the field of Film Theory. Following technical and narrative 
criteria, he defined four taxonomic categories of documentaries (Nichols, 1991: 65-106) that he later expanded to six (Nichols, 2001: 142-212). Following the order that Nichols himself uses, these are expository, observational, participatory, reflexive, poetic and performative.

Expository documentaries emerged from the British School through the work of John Grierson as a result of his disenchantment with the entertainment meted out by fictional cinema. In these documentaries there is an omniscient voice guiding the narrative of the plot which the images serve to illustrate. Asynchronous sound predominates and the montage serves to establish and maintain rhetorical rather than spatial or temporal continuity. The voice of authority in this category of documentary is the text itself, not the voices that have been brought in to form part of it.

Observational documentaries, which grew out of objections to the moralizing quality of the expository documentary, are characterized by the committed non-intervention of the film-maker and therefore by the total relinquishing of control. They are based on continuous montage to strengthen the impression of genuine temporality; there is no explicit narrator, no background music, no on-screen text, no reconstruction. Interviews are the exception to this, given that this is a modality committed to immediacy, intimacy and the personal.

Participatory documentaries attempt to make the perspective of the film-maker explicit. Thus, this is the type of film that incorporates most interviews and in which the voice of the narrator is not held back until post-production; rather, the film-maker intervenes and can be heard speaking at the places where the events unfold. As opposed to the expository documentary, the voice of authority is no longer a product of the text; rather, here it belongs to the social agents whose comments shape the logic of the argument.

Reflexive documentaries grow out of a desire to make the conventions of the representation itself more evident and to put the impression of reality to the test. In this way, the film-maker speaks less of the historical world or of ethical questions, in order to focus instead on the devices of the representation of reality themselves and on the production of the documentary. On many occasions, professional actors are used to represent what the documentary could have been capable of communicating.

The poetic documentary focuses more on stylistic and technical aspects than on the actual representation of reality. So it sacrifices the conventions of continuous montage and does not pretend that the space and time where the actions occur can be understood. Interest in this type of documentary resides in the exploration of associations and patterns related to temporal rhythms and in spatial juxtapositions.

Finally, the performative documentary is characterized by the development of a specific embodied knowledge that becomes incarnate in a subjectivity that moves far from the logic of the objective. In virtue of this, the performative documentary unrelentingly questions the presence of an omniscient subject 
able to dominate the whole of reality and functions through the transmission of subjective experiences.

Despite the fact that this classification has acquired considerable prestige, it has also been harshly criticized by different authors. Stella Bruzzi (2000), for example, focused her criticism on the performative mode of representation. For Bruzzi, this term must be returned to its Derridean origins and, making use of Judith Butler's theory, she reassigns this notion, linking it to the nature of the documentary. In this way, she defends the idea that performativity is the notion that allows us to overcome the eternal debate between the genres of fiction and non-fiction. Thus, Bruzzi allies herself with the cognitive theoreticians Noëll Carroll $(1996,1998)$ and Carl Platinga $(1997,2005)$ in their definition of the documentary. At the same time, Bruzzi defends Michael Renov's (2004) notion of desire as the performative driving force of the documentary film.

However, the two voices that have received most criticism are the poetic and reflexive voices. For Matthew Bernstein (1998: 413), both these voices respond to a post-structuralist moment when Nichols placed more weight on formal contextual elements than on the textual elements. The reflexive and poetic voices are particularly characterized by the intentions with which the film-maker approaches them. Thus, reflexive documentaries are those that question the very documentary device itself, while poetic documentaries are those that aim to be an aesthetic creation. However, beyond this intentionality, there are no other formal criteria that define them. That is why, among many other reasons, these voices cannot be considered to be documentary modes on the same level as the other four. The reflexive and the poetic, more than formal groupings, are just modes that explain or relate the cinematographic plot.

In addition, in the case of the reflexive voice, the form can even lead to a conceptual tension that invalidates it. Jay Ruby is one of the documentary theoreticians who has most insisted that one of the moral obligations of this genre is precisely to be reflexive (Ruby, 1998, 2000). However, as Butchart (2006) notes, Ruby's conception of reflexivity does not correspond to Nichols' voice. In contrast to Nichols' notion, Ruby understands reflexivity as the capacity of the documentary to morally influence the audience with respect to a theme or problem of reality, showing a plurality of voices and the deepest research possible. So, the reflexivity that Ruby defends could be achieved through any of the other voices Nichols endorses.

In this way, due to the criticism that these two documentary voices have received, in this study we propose the following first working hypothesis: there are documentary modes that do not form part of Nichols' taxonomy due to the lack of agreement among theoreticians of the documentary. To determine the truth of this hypothesis, it is necessary to answer the following research question: What degree of agreement exists with respect to the six modes of the documentary defined by Nichols?

In order to tackle this issue, this study has to use methodological tools that will allow us to determine the degree of agreement with respect to a 
classification or taxonomy. Such a study requires that we use tools to analyse opinion based on multivariate statistics. However, in the humanities, where Film Studies is traditionally located (Andrew, 2009), research has been based on heuristic and qualitative methods; therefore, there are few examples that this study can refer back to.

However, with the explosion of digital humanities, there are more and more researchers in the field of the humanities who adopt methodologies based on the use of computational tools in order to tackle the topics of their studies from new perspectives. In this way, statistical analysis has been performed on the literary genres that constitute the works of the British Enlightenment (Moretti, 2007) and we have seen predictive analysis of the meaning of cinematographic works through a sophisticated algorithm (Wasserman et al., 2015).

Following these lines, this study contemplates the possibility of applying methodologies of opinion analysis in order to carry out a systematization of Nichols' taxonomy. Such methodologies, based on cluster analysis, have emerged from the cognitive sciences and have been very widely used in information architecture (Rosenfeld et al., 2015) to reconstruct browsing experiences or to create computational heuristics (Pang and Lee, 2008). In this way, the second hypothesis in this study emerges: through the use of multivariate statistics it is possible to overcome the discrepancies concerning the modes of documentary by tracing the mental patterns of subjects who are well acquainted with theory. Consequently, the second research question can be stated as: Can we apply a quantitative methodology to the study of the opinions of those subjects who know and are well acquainted with Nichols' modes of the documentary?

\section{METHODS}

\section{Starting point: mapping out the bibliography}

Our research begins with a review to map out the bibliography written by Nichols in order to establish an initial taxonomy of the documentary voices. By a review to map out or systematic mapping, we mean a review whose objective is to 'map out and categorize existing literature from which to commission further reviews and/or primary research by identifying gaps in the research literature' (Grant and Booth, 2009). The systematic mapping out is carried out in a tabular fashion and can be seen in Table 1, which summarizes the conclusions of Nichols' studies (1991, 1994, 2001, 2002a, 2002b, 2006) that deal with the subject of the voices of documentary.

\section{Validating the mapping: semi-structured interviews and the persona method}

The tree of classifications derived from the previous mapping review is examined by five experts through semi-structured interviews (Kvale, 2007). This procedure allows us to validate the taxonomy and complete it with 


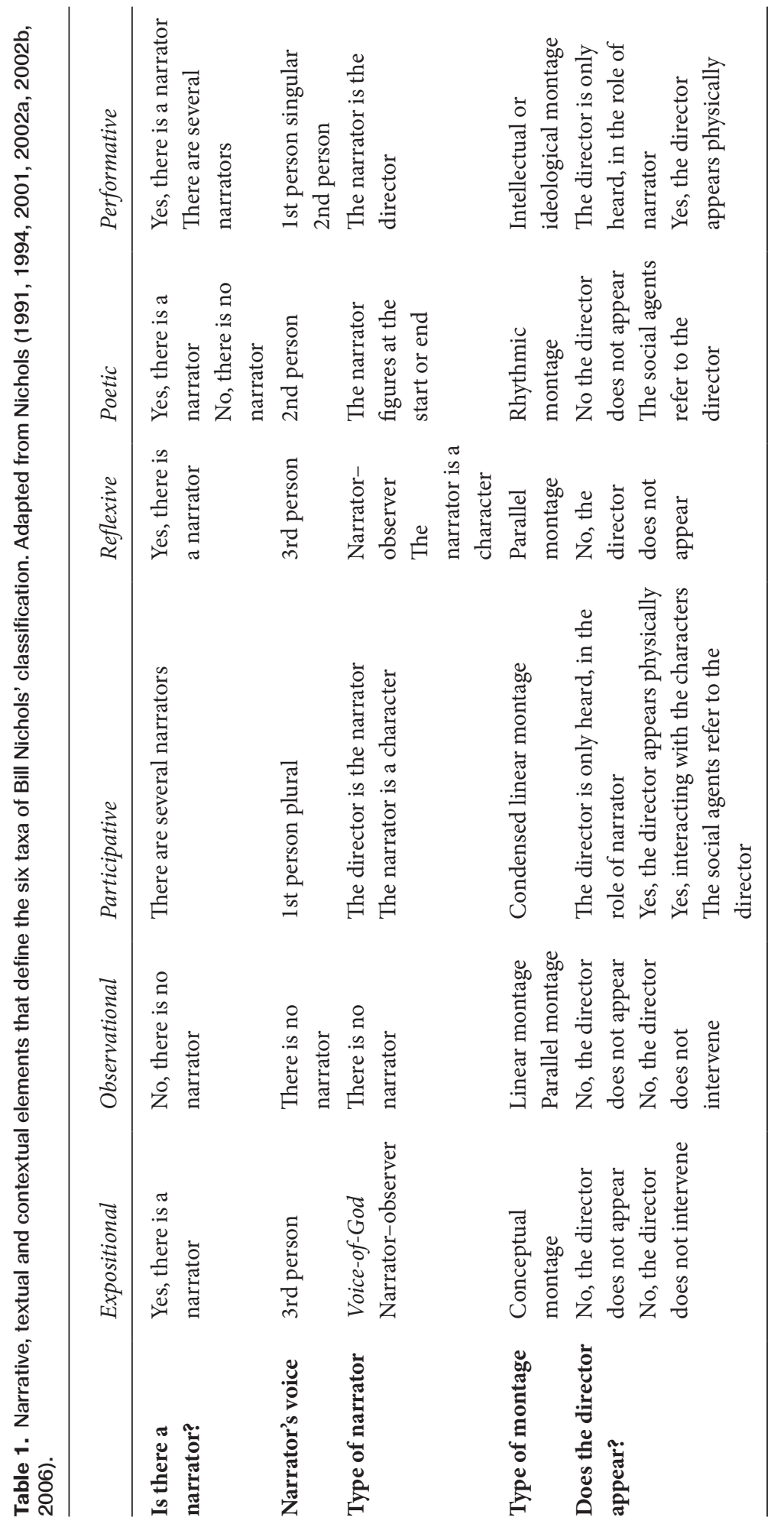




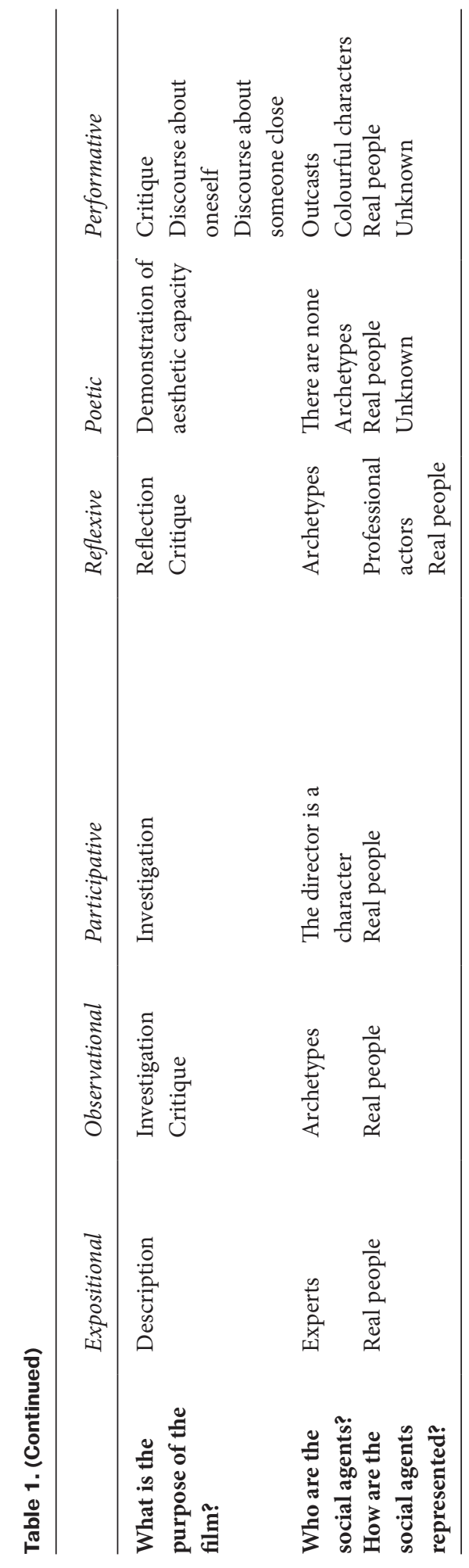


Table 2. Semi-structured interviews.

\begin{tabular}{|c|c|}
\hline Parts of the interview & Objective \\
\hline $\begin{array}{l}\text { Part I: Presentation of the interviewer } \\
\text { and the research }\end{array}$ & $\begin{array}{l}\text { To situate the interviewee: Who am I? } \\
\text { What discipline do I work in? The main } \\
\text { objectives of the research. }\end{array}$ \\
\hline Part II: Knowledge of Nichols' theory & $\begin{array}{l}\text { To learn how the interviewees assess their } \\
\text { own degree of knowledge of Nichols' } \\
\text { taxonomy. }\end{array}$ \\
\hline Part III: Importance of the taxonomy & $\begin{array}{l}\text { To assess the validity of Nichols' taxonomy } \\
\text { with respect to other taxonomies that the } \\
\text { interviewees may know. }\end{array}$ \\
\hline $\begin{array}{l}\text { Part IV: Validating and completing the } \\
\text { tree obtained from the review of the } \\
\text { mapping }\end{array}$ & $\begin{array}{l}\text { To show the interviewees the tree that was } \\
\text { derived from the review of the mapping } \\
\text { and to assess its validity. To complete it by } \\
\text { adding descriptors or eliminating those } \\
\text { that the interviewee thinks are incorrect. }\end{array}$ \\
\hline $\begin{array}{l}\text { Part V: Definition of potential users of } \\
\text { the taxonomy }\end{array}$ & $\begin{array}{l}\text { To establish what types of users may be } \\
\text { interested in this taxonomy. A constitutive } \\
\text { part of the persona method. }\end{array}$ \\
\hline Part VI: Importance of the research & $\begin{array}{l}\text { To assess the importance that the } \\
\text { interviewees give to this research. To close } \\
\text { the interview. }\end{array}$ \\
\hline
\end{tabular}

perspectives on and experiences of the theory of the documentary provided by the experts interviewed.

The background of the experts is both academic and professional, and therefore these interviews are considered to be of experts. As Hertz and Imber (1995) warn, one of the characteristics of interviews with experts is that the customary hierarchy of the roles in an interview, in which the researcher is in charge of steering the conversation, can be reversed. Experts are accustomed to being asked questions on the subject and so the interviewer must have advanced knowledge of the subject and dominate the specialist vocabulary and literature. In this way, the interviewer who demonstrates this knowledge will gain the respect of the interviewees and will restore balance to the interview which will facilitate the acquisition of relevant data.

Details of the script of the interview are given in Table 2. In order to avoid bias, the interviewer avoided the use of examples and mentioning the names of directors or the titles of films in the dialogue. When dealing with interviewing experts, the number of people to be interviewed should be between 5 and 10, according to Baker and Edwards (2012: 8). In the present research, we decided to interview 5 experts on Nichols' theory of the documentary, given furthermore that the interviews are exploratory, not 
definitional. By comparing the 5 interviews we aimed to obtain a second taxonomy which we would be able to verify in the third stage of the method.

The interviews were recorded using the application VoiceRecorder and complete transcripts of them were written out, placing the emphasis on the content, not on the language; that is, we did not take into account dialectic or phonetic aspects of what was said. The transcripts were written out using the Microsoft Word word-processing program from the Office suite. Finally, the analysis of the interviews was based on condensing the content (Kvale, 2010: 205). That is, extracts of each of the interviews that corresponded to the different points in the script were grouped together in order to extract partial conclusions, particularly from sections II, III, V and VI. In the same way, the extracts from which we removed or to which we added descriptors were analysed separately. With regard to phase IV, we used categorized tabulated analysis.

\section{Definition of the taxonomy: card sorting and the persona method}

The taxonomy that emerged overall from pooling the interviews was systematized using the card sorting technique - a procedure that originated in cognitive science and is also applied in many other fields such as, for example, information architecture, and which is based on cluster analysis. The card sorting technique is based on observation of how the users group together and associate a predetermined number of cards labelled in different themed categories (Rosenfeld et al., 2015; Spencer, 2009). It is an opinion sampling technique that allows the mental models of as many subjects as convenient to be grouped together under one overarching pattern.

We carried out a closed card sorting exercise (Rosenfeld et al., 2015; Spencer, 2009) in which the categories that the cards are to be sorted into are predefined and users just have to place each card into the category they consider the most appropriate. This type of test, in addition to being very widely used in web design, has also been applied to verify whether a classification that already exists can be understood by the user (Nurmuliani et al., 2004) or to classify elements that have not been classified previously (Rugg et al., 1992).

The experimental method designed for this research was to use as many cards as emerged from the analysis of the interviews, each of them repeated six times and labelled with one of the six types of voice of the documentary. So, the subjects who take part in the test would have six sets of cards, each labelled with the name of a taxon. Seven closed categories were defined: one for each voice of the documentary and a seventh called 'Not assigned' where the subjects place all the cards which, despite being labelled with the name of a taxon, cannot be assigned to it. The test was conducted remotely (Spencer, 2009) using the UserZoom software, which is accessible at http://www.userzoom.com. 
The result of the experiment is a dendrogram that will provide us with two different types of information. Firstly, it explains which descriptors, that is, which formal elements, define each one of the taxa. Secondly, it establishes which of the formal elements that define each taxon are closer to each other and therefore more important when it comes to defining the voice of a documentary. To complement this latter information, we review the frequency matrices for each element - or the cluster matrices - from which we determine the degree of inter-subject agreement and therefore the relative weight of each element in the definition of each taxon.

It is difficult to determine the optimum number of subjects for the experiment (Spencer, 2009). However, for Nielsen (2004), it is necessary to have between 15 and 20 participants in order to obtain correlations of regression coefficients of 0.90 to 0.93 . Meanwhile, Tullis and Wood (2004) recommend from 20 to 30 , taking into account that, with 30 participants, the correlation is potentially 0.98 . In this study, we decided that we needed 15 participants. We initially contacted 83 people, 46 of whom began the test. Of those, only 18 managed to complete it; this gave us a final number of subjects within the range that generates significant coefficients.

Finally, to determine what type of users should participate in the card sorting exercise, we used the 'persona' method, which is used to create profiles that represent the different types of users who may be interested in the classification. The persona method is widely used in online and technological applications, as well as in advertising (Cooper et al., 2003; Pruitt and Grudin, 2003), although this study was conducted to determine what type of people would be interested in the systematization of Nichols' taxonomy. The profile of a subject is drawn up based on part $\mathrm{V}$ of the semi-structured interviews. Participation is voluntary and there is no type of incentive at all so as not to compromise the results through recruiting opportunistic subjects. The invitations were sent out using an institutional email in order to show the professional status and serious nature of the project.

\section{RESULTS}

\section{The opinion of the experts}

Firstly, we assessed the level of knowledge of the experts we interviewed regarding the theory of documentaries. In most cases, they reported their own level of knowledge of the Nichols theory as being high or very high. However, they also stated that the classification is the subject of considerable debate due to the volatile nature of the documentary genre, which does not prevent the level of knowledge of the taxonomy from remaining high, at a theoretical level. The last of the experts we interviewed was the one who expressed the greatest rejection of Nichols' taxonomy, despite having a high level of knowledge of it, because it was seen as being insufficient and mistaken: 
My degree of knowledge is quite deep because I have used it many times. What happens is that even Bill Nichols himself has changed his outlook towards some of them, so what he has opened up is a debate ... (Expert 1)

Evidence of my familiarity ... Could the fact that I translated the only book that has been translated in Spain on Bill Nichols be evidence that I have a certain familiarity with the author? (Expert 2)

The degree of knowledge that I have of what Nichols has claimed is high despite the fact that there are things that even today I still do not fully understand or that I do not agree with. (Expert 4)

Nichols, for me, was one of the first people to provoke in me a very direct rejection of the type of classification of the documentary or, simply, the conception of documentary that he had. (Expert 5)

Concerning the evaluation of Nichols' taxonomy, all the experts coincided in the importance it had in the general theory of the documentary. Although they knew other taxonomies, such as those of Barnow (1993) or Plantinga (1997), they all said that Nichols' theoretical taxonomy was the most used, justified and evaluated in studies of the documentary genre:

I consider that it has been tremendously useful. And that is also why it has been cited so often. (Expert 1)

Let's say that the most normative is Nichols' taxonomy, because it is the most straightforward to explain and the easiest to transmit. (Expert 2)

Yes, Nichols has always been a reference within the world of cinema and of the essay. (Expert 3)

After assessing these two variables - self-evaluation of their knowledge of Nichols' theory and the degree of importance of the taxonomy - the internal validity of these interviews is completely justified. Therefore, we can derive from them the corresponding assessments of the textual, narrative and contextual elements that define each of the taxa in Nichols' categorization and how they are distributed.

Once we obtained the analysis tables for each individual interview, we drew up a final table summarizing the frequencies with which each of the different descriptors figured in the interviews. Table 3 shows these frequencies. We only selected the values of the variables that had a frequency of 3 or more from the 5 interviews: that is, those descriptors that had figured in 3 or more interviews.

We should also note the strength of the rejection expressed by the last expert to be interviewed with regard to the validity of the 'poetic' documentary taxon.

... for me, of the six categories that he proposes, that one of them should be the poetic documentary, for me, I just don't know ... for me, 


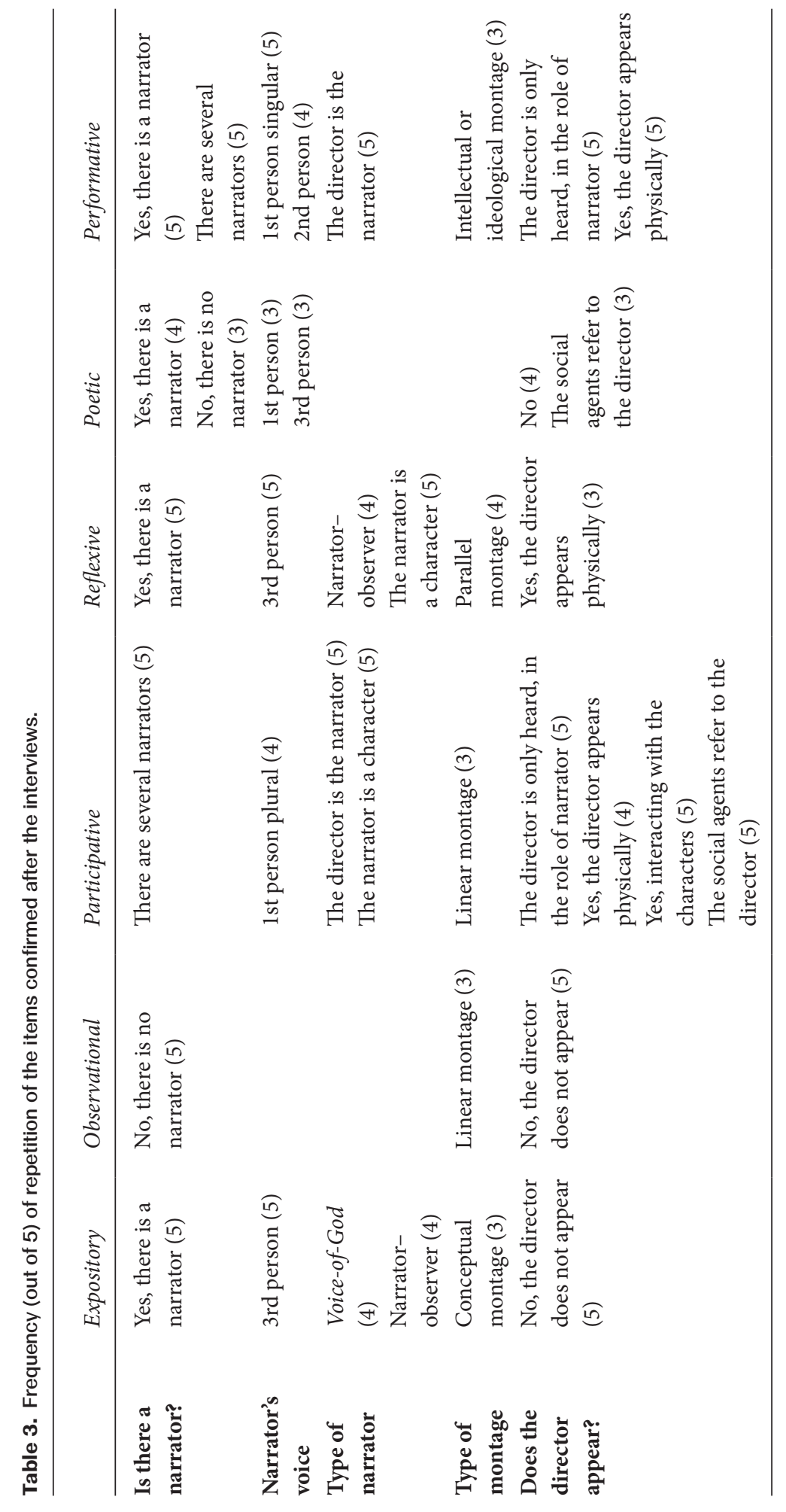




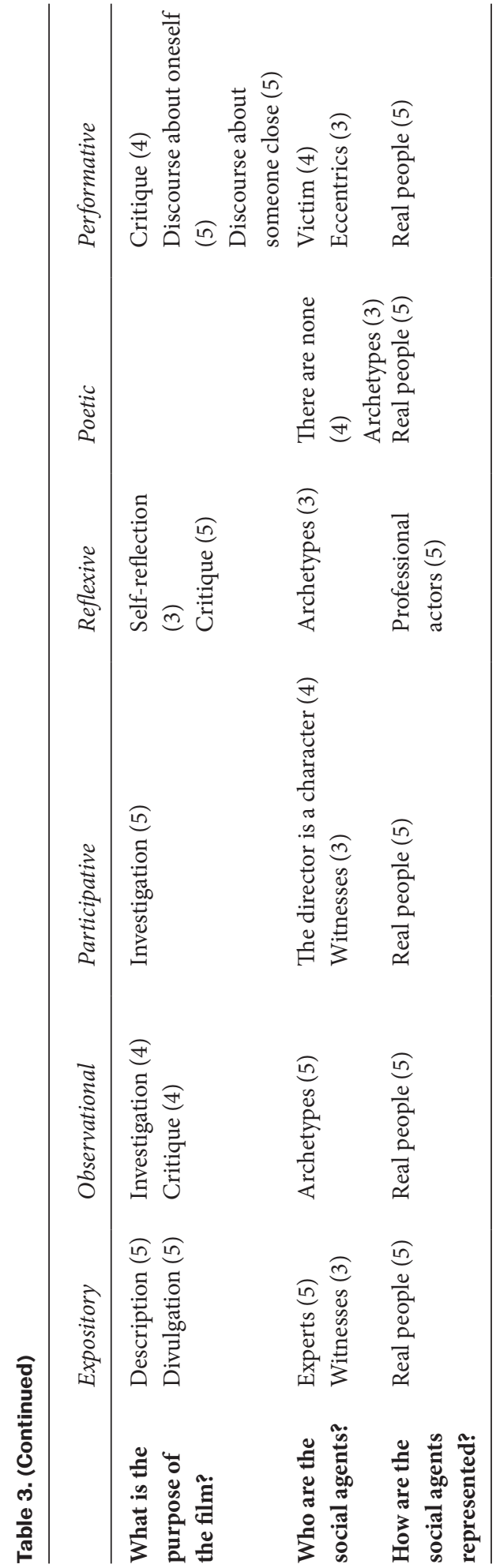


from the start, right from the beginning it makes me ask: But what are you talking about? I mean, because in reality it is a category we could include any created work in. (Expert 5)

After detailed analysis of the five interviews, the number of variables was reduced from the 40 we obtained after the systematic review to just 36 variables. As can be seen in Table 3, the taxa expository, observational, participative and performative are those that have the highest frequencies in all the variables that describe them. However, in the taxa reflexive and poetic, these frequencies are lower, which in the latter case is in agreement with the rejection expressed by the last expert interviewed with respect to the validity of the last taxon. So, we have to consider this fact as an inductive hypothesis.

\section{Personas}

Based on part $\mathrm{V}$ of the interviews, we determined three types of profiles of archetypal characters who would potentially be interested in this systematization: academics, film and cinema students, and producers or film-makers.

In general, those who study the documentary could be interested in being able to work on something that has been systematized ... Academics and students, obviously. (Expert 1)

I would say that it will be of more interest to film-makers and institutions, and also, television ... institutions such as associations of producers or even public institutions. (Expert 2)

Fundamentally, yes, it is of interest to the person who is going to make, the person who is going to take on a documentary. (Expert 3)

Those who could be most interested in this are the academic world in general, much more than directors in the professional world. (Expert 4)

I believe that it will be of much more interest to those who theorize about and study it than to film-makers themselves. (Expert 5)

In this way, we concluded that it is the academic profile that the experts are in most agreement over; while the degree of agreement between them with regard to the film-maker and cinema student profiles is lower. So, we decided to recruit more theoreticians and university lecturers than directors or students. Of the 18 users, 11 were academics, 3 were directors or film-makers and 4 were students.

\section{Card sorting}

Each one of the 36 variables that emerged from the interviews was labelled with the name of each of the six taxa in Nichols' classification. In this way, we produced 216 cards that the subjects placed in the 7 closed categories: 6 
corresponding to the six taxa and a 7th called 'Not assigned' where the users placed the cards that, despite being labelled with the name of a taxon, were not assigned to it.

As a result of the analysis of this distribution, we drew up the dendrogram shown in Figure 1. This dendrogram allows us to group the cards into clusters according to the degree of similarity between the arrangements of each of the subjects who took part in the card sorting exercise. In addition, it also shows which formal elements define each of the taxa and which of the formal elements that define each taxon are closest to each other and therefore most important when it comes to defining each documentary voice.

The hierarchy was constructed using the average linkage method, which starts with the construction of a similarity matrix that assumes an increasing scale of similarity with an interval of $[0,1]$ where 0 corresponds to the most similarity (that between an item and itself) and 1 corresponds to minimum similarity. The dendrogram constructed from this matrix produced a taxonomy of five clusters with an inter-cluster level of similarity of 0.715 , which was the most significant.

Of these five, one corresponded to the concepts linked to the category 'Not assigned' and with other concepts that have no significant similarity with the rest, as shown in Figure 1. The other four taxa, in contrast, were those of Nichols' taxonomy that were confirmed after the systematization and which correspond to the taxa expository, observational, performative and participative. Consequently, the systematization of Nichols' classification confirms that the existence of two of the taxa defined by him are not justified if we consider textual, narrative and contextual criteria. The taxa reflexive and poetic, therefore, cannot be considered documentary voices, confirming the hypothesis that emerged at the inductive level in the interviews.

Figure 2 shows the individual and amplified dendrograms corresponding to each of these taxa, which provide information concerning how strong or weak the interaction between each one of the descriptors is with the taxon that it defines. In addition, we can extract the frequencies with which each card or concept was placed in each classification. The analysis of these tables is the best possible indicator of which formal elements best define each taxon. To determine which formal criteria define a taxon, we took a level of inter-subject agreement of greater than 72 percent. This value was chosen since it indicates agreement between 13 or more subjects; which is the proportion that continues to produce regression coefficients close to 0.90 (Nielsen, 2004).

Table 4 shows how Nichols' classification looks once it has been systematized through application of the mixed methodology used here. As can be seen, the claim that all documentaries can be defined using narrative, textual and contextual criteria remains correct. Of all of them, the only one that has been lost is that which referred to the nature of the social agents; a formal contextual criterion related to which, however, the purpose of the documentary remains in the classification. Compared to Table 3, the first difference, as we 


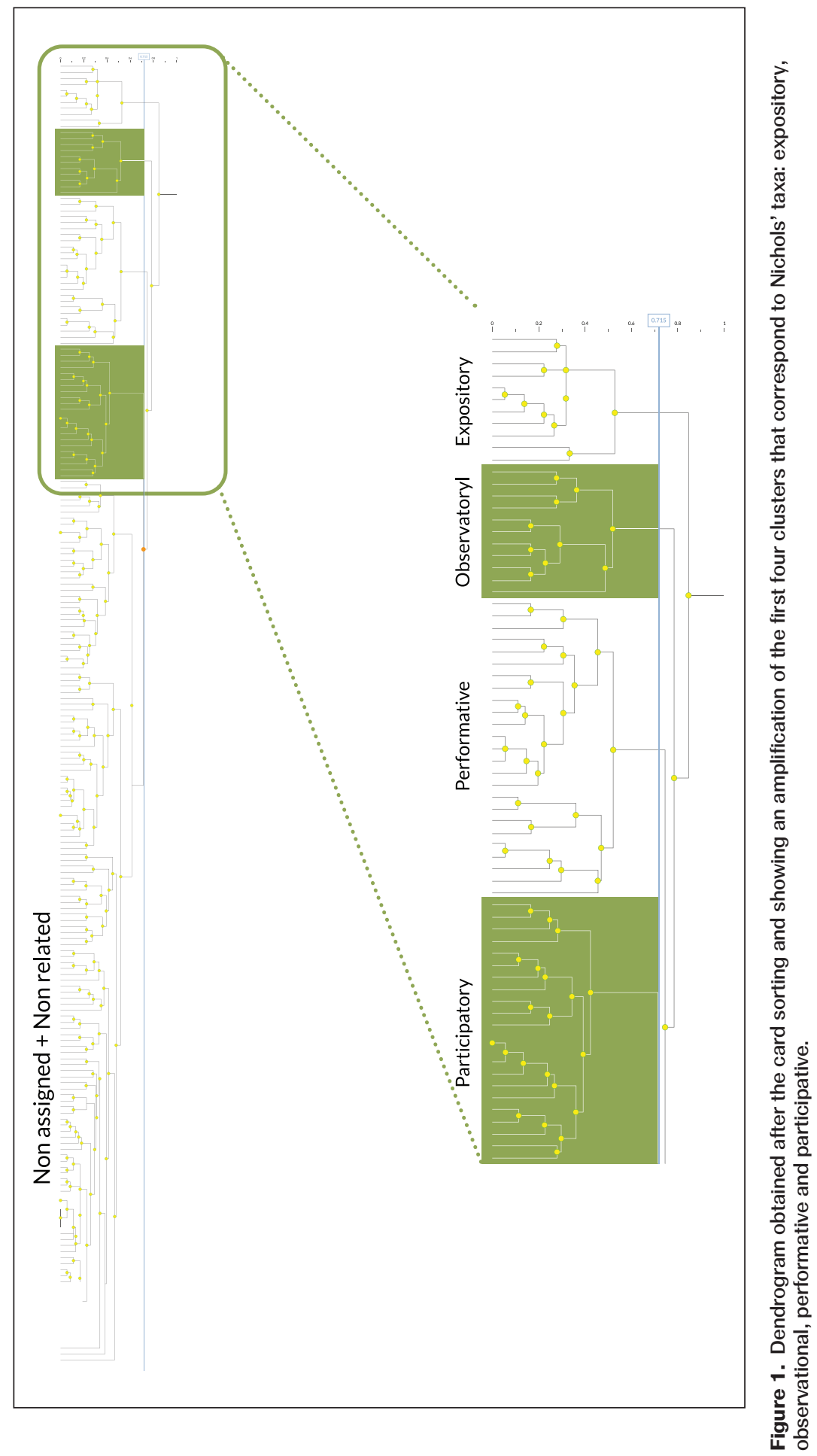


have already mentioned, is the disappearance of the reflexive and poetic taxa. Furthermore, the number of formal criteria has been reduced from 36 to 21, so each type of documentary is defined by fewer formal aspects. Expository is now defined by 8 aspects, participative by 7 , performative by 9 , and finally observational by 5 .

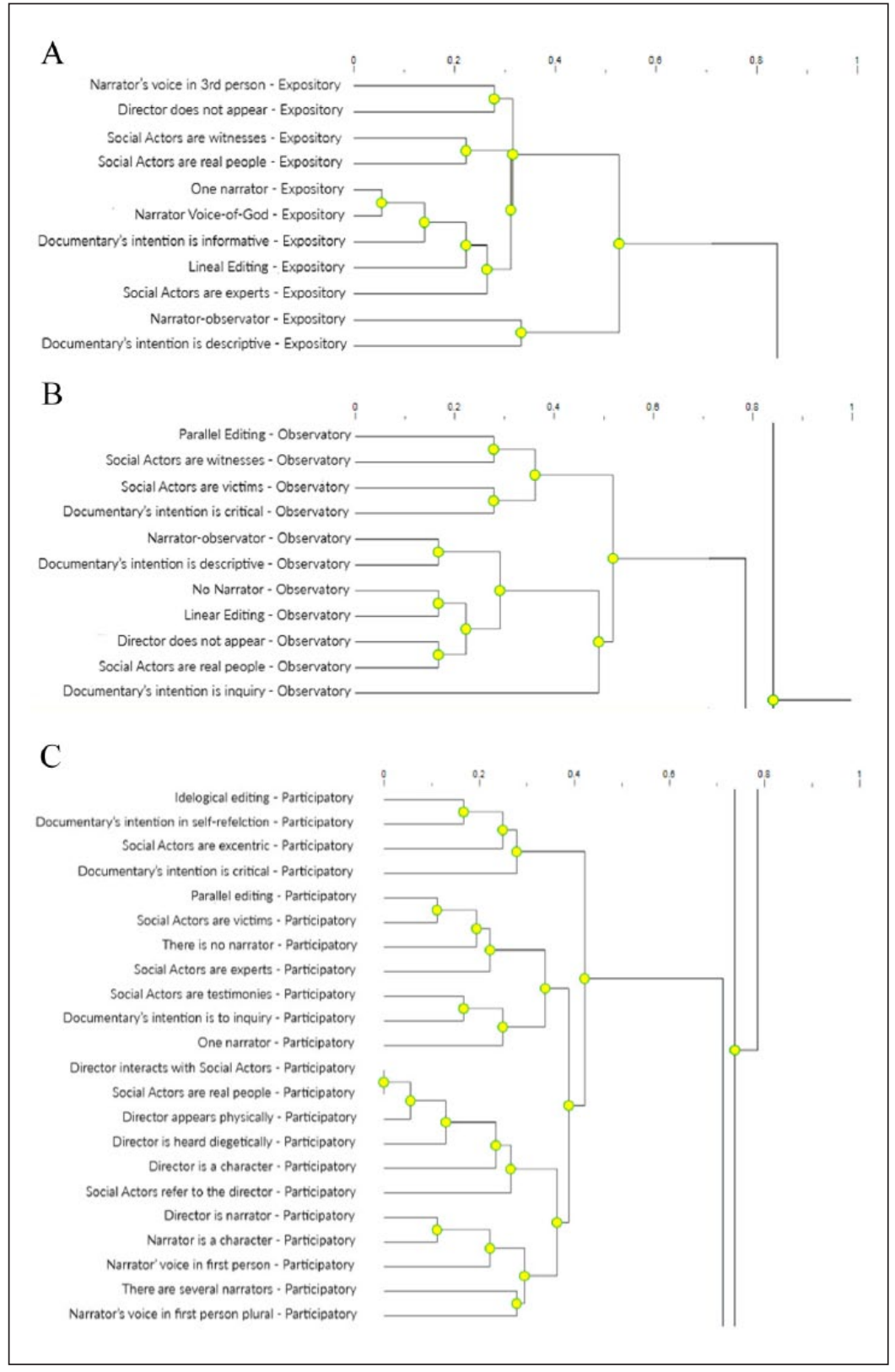

Figure 2. (Continued) 


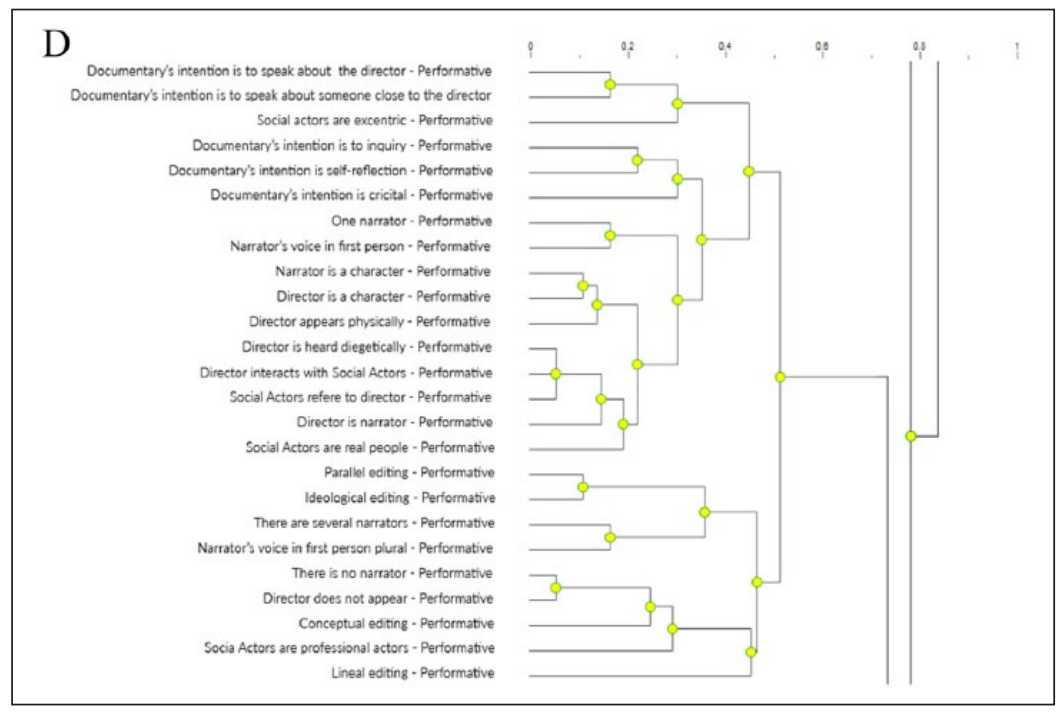

Figure 2. Detailed dendrograms of the four clusters corresponding to Nichols' modes of the documentary: (A) expository, (B) observational, (C) participative and (D) performative.

\section{CONCLUSIONS AND DISCUSSION}

As we state in the introduction, this study comes in the wake of the work by Barry Salt (1974 and 2006) on the statistical analysis of cinema. Salt stood alone until well into the 1990s in defending the possibility of going beyond the heuristic analysis of cinema, and approaching its analytical study from a quantitative perspective. Over the years, new scholars of the Theory of Cinema have joined this trend. For example, Charles O'Brien studied the impact of the appearance of the talking movie on French and American cinematography from this perspective (O’Brien, 2005). Another example is Yuri Tsivian, who at present is developing the Cinemetrics project, the aim of which is to compare the average duration of the shots in as many films as possible in order to reveal regularities that support or refute schools, styles or authorship that have been defended heuristically (Tsivian, 2009). More recently, Nick Redfern has been working and advocating for introducing quantitative methods and perspectives to the study of film, moving the field of Film Studies into, as he states, 'Study of film' (Redfern, 2013, 2014).

Along these lines, the consonance of the methodological strategy adopted in this study is justified; it has been used to systematize Nichols' taxonomy of documentaries thanks to a combination of qualitative and quantitative techniques. Carrying out an orderly review of the mapping, ethnographic interviews and card sorting has allowed us to understand better how to classify documentaries via formal narrative, textual and contextual criteria, taking as our starting point the essays of Nichols. The main result of this study is a 


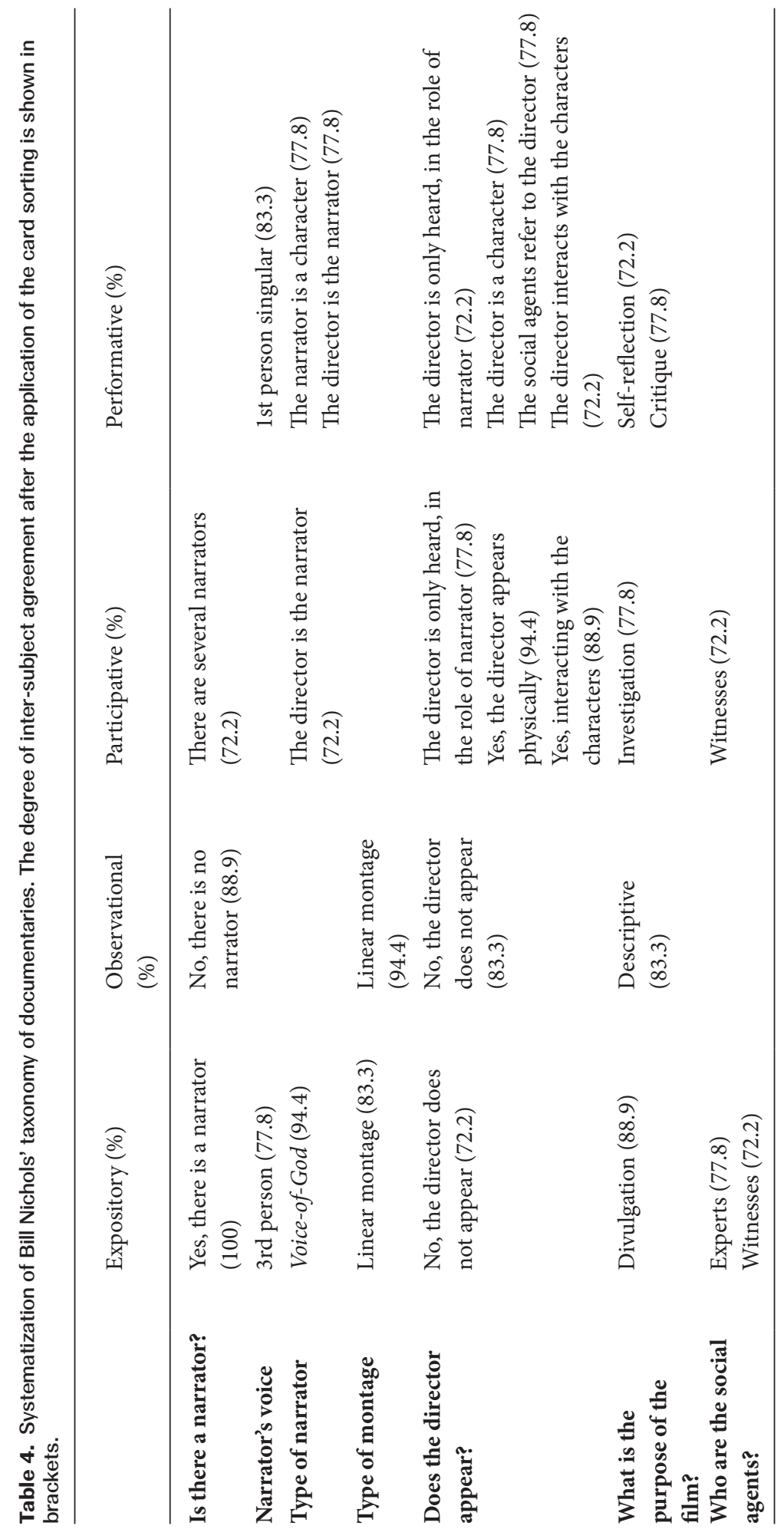


taxonomy that consists of 21 formal elements (textual, contextual and narrative) grouped into 4 documentary voices. In this way, from the 6 initial modes proposed by Nichols, the poetic and reflexive voices have been dropped.

These results are in line with the doubts we refer to in the introduction, expressed by Bernstein (1998: 413) and Butchart (2006), who maintained that Nichols' introduction of those voices into the taxonomy of documentaries was motivated by a specific post-structuralist moment. However, Stella Bruzzi's (2000) questioning of the performative voice is not reflected in the analysis of opinion that we have carried out which, in contrast, confirms it.

When explanatory theories or models are proposed, on the majority of occasions classifications of objects of study are put forward. This study is based on a clear desire to generate methodologies that serve to validate categorizations from an evidence-based perspective. Just as in the case of Nichols' classification of documentaries, many of the theoretical systems spring from intuitions and inductive methods. The methodological tool that this study has brought to the debate allows us to go beyond those intuitions, bringing scientific validity to a theoretical model that is very firmly accepted in the academic community. This study demonstrates that, in the field of visual communication, methodologies can be generated which borrow from multivariate analysis to validate categorizations from an evidence-based perspective rather than complement those methods based on intuition and inductive methods.

\section{F U N D ING}

This research received no specific grant from any funding agency in the public, commercial, or not-for-profit sectors and there is no conflict of interest.

\section{ORCIDID}

Sergio Villanueva Baselga (DD https://orcid.org/0000-0003-4447-151X

\section{REFERENCES}

Andrew D (2009) The core and the flow of Film Studies. Critical Inquiry 35(4): 879-915.

Baker SE and Edwards R (2012) How many qualitative interviews is enough? Expert voices and early career reflections on sampling and cases in qualitative research. Review paper, National Centre for Research

Methods, Economic and Social Research Council, University of Southampton.

Barnow E (1993) Documentary: A History of Non-Fiction Film. Oxford: Oxford University Press.

Bernstein M (1998) Documentaphobia and mixed modes. In: Grant BK and Sloniowski J (eds) Documenting the Documentary: Close Readings of Documentary Film and Video. Detroit: Wayne State University Press. 
Bruzzi S (2000) New Documentary. London: Routledge.

Butchart GC (2006) On ethics and documentary: A real and actual truth. Communication Theory 16(4): 427.

Carroll N (1996) Theorizing the Moving Image. Cambridge: Cambridge University Press.

Carroll N (1998) Engaging the Moving Image. New Haven, CT: Sheridan Books/Yale University.

Cattani G et al. (2008) The structure of consensus: Network ties, legitimation, and exit rates of U.S. feature film producer organizations. Administrative Science Quarterly 53(1): 145-182.

Chapan J (2009) Issues in Contemporary Documentary. Cambridge: Polity Press.

Cooper A, Reimann R and Cronin D (2003) About Face 3: The Essentials of Interaction Design. New York: Wiley.

Ferrari MJ and Rudd M (2008) Investing in movies. Journal of Asset Management 9: 22-40.

Grant MJ and Booth A (2009) A typology of reviews: An analysis of 14 review types and associated methodologies. Health Information and Libraries Journal 26: 91-108.

Hertz, R y Imber, J.B. (1995) Studying elites using qualitative methods. Thousand Oaks: Sage.

Hsu G (2006) Jacks of all trades and masters of none: Audiences' reactions to spanning genres in feature film production. Administrative Science Quarterly 51(3): 420-450.

Kvale, S (2007) Doing Interviews. London: Sage Research Methods.

Moretti F (2007) Graphs, Maps, Trees: Abstract Models for a Literary History. London: Verso.

Nichols B (1977) Documentary: Theory and practice. Screen 17(4): 24-48.

Nichols B (1991) Representing Reality: Issues and Concepts in Documentary. Bloomington: Indiana University Press.

Nichols B (1994) Blurred Boundaries: Questions of Meaning in Contemporary Culture. Bloomington: Indiana University Press.

Nichols B (2001) Introduction to Documentary. Bloomington: Indiana University Press.

Nichols B (2002a) Los documentales y el modernismo: 1919-1939. Comunicación y Sociedad 14(2): 71-91.

Nichols B (2002b) Documentary film and the modernist avant-garde. Critical Inquiry 27(4): 580-610.

Nichols B (2006) Questions of ethics and documentary film. Archivos 57: $27-45$.

Nielsen J (2004) Card sorting: How many users to test. Alertbox: Current Issues in Web Usability.

Nurmuliani N, Zowghi D and Williams SP (2004) Using card sorting technique to classify requirements change. Proceedings of the 12th IEEE International Requirments Engineering Conference. 
O'Brien C (2005) Cinema's Conversion to Sound: Technology and Film Style in France and the U.S. Bloomington: Indiana University Press.

Pang B and Lee L (2008) Opinion mining and sentiment analysis. Journal Foundations and Trends in Information Retrieval 2(12): 1-135.

Plantinga CR (1997) Rhetoric and Representation in Nonfiction Film. Cambridge: Cambridge University Press.

Plantinga CR (2005) What documentary is, after all. Journal of Aesthetics and Art Criticism 63(2): 105-117.

Pruitt J and Grudin J (2003) Personas: Practice and theory. Proceedings of the 2003 Conference on Designing for User Experiences. New York: ACM.

Redfern N (2013) Film studies and statistical literacy. Media Education Research Journal 4(1): 58-71.

Redfern N (2014) Quantitative methods and the study of film. Invited lecture, University of Glasgow, 14 May.

Renov M (2004) The Subject of Documentary. Minneapolis: University of Minnesota Press.

Rosenfeld L, Morvile P and Arango J (2015) Information Architecture for the World Wide Web. Cambridge: O'Reilly.

Ruby J (1988) The image mirrored: Reflexivity and the documentary film. In: Rosenthal A and Corner J (eds) New Challenges for Documentary. Manchester: Manchester University Press.

Ruby J (2000) Picturing Culture: Explorations of Film and Anthropology. Durham, NC: Duke University Press.

Rugg G et al. (1992) Comparison of sorting techniques in knowledge elicitation. Knowledge Acquisition 4: 279-291.

Salt, B. (1974) Statistical style analysis of motion pictures. Film Quarterly, 28(1): 13-22.

Salt, B (2006) Moving into Pictures: More on Film History, Style, and Analysis. London: Starword.

Spencer D (2009) Card Sorting: Designing Usable Categories. Brooklyn, NY: Rosenfeld Media.

Tsivian Y (2009) Cinemetrics, part of the humanities' cyberinfrastructure. In: Ross $\mathrm{M}$ et al. (eds) Digital Tools in Media Studies. New York: Columbia University Press, 93-100.

Tullis T and Wood L (2004) How many users are enough for a card-sorting study? Proceedings of the 13th Annual Conference of the Usability Professionals Association, Bloomingdale, IL.

Wasserman M et al. (2015) Cross-evaluation of metrics to estimate the significance of creative works. Proceedings of the National Academy of Science 112(5): 1281-1286.

\section{BIOGRAPHICAL NOTES}

SERGIO VILLANUEVA BASELGA is Assistant Professor in the Deparment of Library, Information and Communication, University of Barcelona, and 
postdoctoral researcher at Barcelona Institute for Global Health, Spain. His research focuses on participatory practices in filmmaking and its relation to health narratives. Currently he is researching co-creation methodologies facilitated by Participatory Video to look for innovative ways of addressing health stigmas narratives.

Address: Deparment of Library, Information and Communication, University of Barcelona, Melcior de Palau 140, Barcelona 08014, Spain. [email: sergio.villanueva@ub.edu]

MARIO PÉREZ-MONTORO is a Professor in the Deparment of Library, Information and Communication, University of Barcelona, where he has taught in the areas of interaction design and information visualization for over 10 years. He is currently the Director of the $\mathrm{PhD}$ in Information and Communication Program at this University.

Address: Deparment of Library, Information and Communication, University of Barcelona, Carrer Melcior de Palau 140, Barcelona 09014, Spain. [email: perez-montoro@ub.edu]

LYDIA SÁNCHEZ GÓMEZ is an Associate Professor in the Deparment of Library, Information and Communication, University of Barcelona, Spain, where she teaches Communication Theory. Her research focuses on the democratic quality of media, epistemology and communication theory.

Address: as Mario Pérez-Montoro. [email: lsanchezg@ub.edu] 